\title{
Modelling the system behaviour of wet snow avalanches using an expert system approach for risk management on high alpine traffic roads
}

\author{
A. Zischg ${ }^{1}$, S. Fuchs ${ }^{2}$, M. Keiler ${ }^{3}$, and G. MeißI ${ }^{4}$ \\ ${ }^{1}$ Geo Information Management, Gargazzone, Italy \\ ${ }^{2}$ alpS Centre for Natural Hazard Management, Innsbruck, Austria \\ ${ }^{3}$ Department of Geography and Regional Research, University of Vienna, Austria \\ ${ }^{4}$ Institute of Geography, University of Innsbruck, Austria
}

Received: 15 July 2005 - Revised: 12 October 2005 - Accepted: 12 October 2005 - Published: 31 October 2005

Part of Special Issue "Spatial prediction modeling in natural hazards and risk"

\begin{abstract}
The presented approach describes a model for a rule-based expert system calculating the temporal variability of the release of wet snow avalanches, using the assumption of avalanche triggering without the loading of new snow. The knowledge base of the model is created by using investigations on the system behaviour of wet snow avalanches in the Italian Ortles Alps, and is represented by a fuzzy logic rule-base. Input parameters of the expert system are numerical and linguistic variables, measurable meteorological and topographical factors and observable characteristics of the snow cover. Output of the inference method is the quantified release disposition for wet snow avalanches. Combining topographical parameters and the spatial interpolation of the calculated release disposition a hazard index map is dynamically generated. Furthermore, the spatial and temporal variability of damage potential on roads exposed to wet snow avalanches can be quantified, expressed by the number of persons at risk. The application of the rule base to the available data in the study area generated plausible results. The study demonstrates the potential for the application of expert systems and fuzzy logic in the field of natural hazard monitoring and risk management.
\end{abstract}

\section{Introduction}

Snow avalanches pose a threat to settlements, infrastructure and road networks in alpine environments. In contrast to dry snow and powder avalanches, the movement of wet snow avalanches is characterised by lower velocities combined with high friction coefficients. Thus, wet snow avalanches do not threat significantly settlements or infrastructures located in the valleys but traffic axes in the alpine environ-

Correspondence to: A. Zischg

(a.zischg@geo-im.com) ments, often following the contour lines of hill slopes or crossing avalanche paths in their transition zones. Therefore, avalanches of this type pose a significant threat to road users. To reduce this susceptibility of roads to avalanche hazards, a considerable amount of money has been spent by the public sector to realise technical mitigation measures. As a result, part of the alpine road network is protected by avalanche galleries or has to be permanently or temporarily closed during the winter months, although the road network is endangered only a few days every year. Additionally, limited financial resources of the public sector and the increasing significance of the road network for the local economic activities, an efficient and sustainable policy of public expenditures for protection against natural hazards is needed (Wilhelm, 1997; Margreth et al., 2003). The construction of permanent mitigation measures for the road network would produce very high costs. Consequently, an improvement of organisational measures, lead by an enhancement of early warning and decision support systems (Kienholz, 2003; UN/ISDR, 2004; Bründl et al., 2004), is necessary. Organisational measures like temporary road closures require a well-informed decision maker with profound knowledge of the observed environmental system, the related indicators of critical situations, the related risks and the criteria for raising alarms (Kienholz, 2003). Additionally, during moderate avalanche hazard levels considerable risk peaks occur due to a high traffic density, as pointed out by Zischg et al. (2005). Following the suggestions of that study, the decision process in operational risk management on roads can be enhanced taking into consideration the temporal variability of both, the avalanche hazard potential and the damage potential by computing the avalanche risk in a short-term timeframe.

The aim of this study was to develop an expert system for modelling the system behaviour of wet snow avalanches and determining the number of potentially affected persons on 
roads, based on the observation of the environmental conditions and the traffic density.

Apart from expert systems, either information systems or decision support systems could be used to enhance experts' and decision makers' knowledge for road risk management (Sailer, 2001; Kienholz, 2003; Bründl et al., 2004). While information systems provide raw data and information, decision support systems provide purpose-built and prepared information (Mittra, 1986; Sprague and Watson, 1986). Whereas both system architectures provide different types of information about the system behaviour, they do not provide decisions. In contrast, expert systems simulate human reasoning about a problem domain, rather than simulating the domain itself (Jackson, 1999). Expert systems perform reasoning over representation of human knowledge by heuristic or approximate methods. In this way, the computer programs are designed by crystallising the expert's problemsolving logic in a knowledge base that non-expert users or experts in other disciplines can then apply to similar problems with data related to those problems and their context (Rodriguez-Bachiller and Glasson, 2004). As synonym for the term "expert system", the term "knowledge-based system" sometimes is used, although the latter is more general and usually do not include algorithmic or statistical methods (Jackson, 1999). Fundamental topics in expert systems are the transfer and the transformation of potential problemsolving expertise from some knowledge source to a program, the representation of knowledge, the modelling of the reasoning process, and the explanation of the computed solutions (Jackson, 1999). These topics determine the structure and the design of expert systems. The knowledge base is represented in the form of if-then rules. By a user interface or direct connections with measurement instruments, the needed data about the observed system can be inserted into an implemented database. Based on this input data, the rule base is queried by the inference engine. The inference engine identifies which rules provide values for the current environmental conditions and computes the final conclusion of all rules (Rodriguez-Bachiller and Glasson, 2004).

One characteristic of expert systems is the explanation of the computed results of the inference procedure. It is the capacity of explaining why and how a particular conclusion is computed, simply detailing for the user the chain of conditions and the fulfilment of the applied rules. Another characteristic of expert systems is the separation between the knowledge involved in problem-solving and the knowledge involved in designing the inference engine (RodriguezBachiller and Glasson, 2004). This separation leads to the possibility of amplification and enhancement of the rule base by the expert, independent from the version of the software. Therefore, the technique for transformation of the expert's knowledge into a rule base and the amplification of the rule base by the user, the so called "knowledge acquisition" or "knowledge engineering" becomes the fundamental step in building expert systems.

In the past decades, several expert systems for the application in avalanche forecasting and in operational risk man- agement were developed. Bolognesi (1993) and Bolognesi et al. (1994) presented an expert system for the avalanche forecasting on a local scale (AVALOG), Schweizer and Föhn (1996), Schweizer et al. (1994) and Brabec (2001) showed an approach for the avalanche forecasting on a regional scale (DAVOS, MODUL, NXD-REG). An expert system for the determination of avalanche release zones on the basis of digital terrain models was pointed out by Buisson and Charlier (1989). Buisson and Charlier (1993) showed an approach for the analysis of the characteristics of avalanche paths (ELSA). An approach for the forecasting of the avalanche triggering probability (SAFRAN-CROCUS-MEPRA) was demonstrated by Buisson and Giraud (1995) and Durand et al. (1999). Kleemayr et al. (2000) developed a numerical avalanche prediction model (NAFT) based on the combination of statistical analysis, artificial neural networks and a fuzzy-expert system. McClung (1995a, b) developed an expert system for the interpretation of snow profiles.

These approaches focused on the estimation of the avalanche hazard potential, particularly with respect to the triggering of dry snow slab avalanches. None of the cited studies focused either on the triggering probability of wet snow avalanches or on the related damage potential. Furthermore, the uncertainties in the computing process mostly are not taken into account. The study presented in this paper focussed on the determination and representation of the temporal variability of both risk factors, the hazard potential and the damage potential. In this work, the expected fatalities on roads due to wet snow avalanches were calculated based on the current environmental conditions (snow cover characteristics, snow and air temperature). The system behaviour of wet snow avalanches was modelled on the basis of the available data and the existing knowledge about this process. The uncertainties in the used modelling approach for the representation of the system behaviour were taken into consideration. The short-term variability analysis of the behaviour of the system "avalanche prone road" - expressed by the time-variable "avalanche related damage potential on roads" - requires the observation of the diurnal variability of the hazard potential and the damage potential.

The highly variable hazard potential of avalanches consists of three different phases characterised by the process (Zimmermann et al., 1997). The phase "basic disposition" is the general long-term tendency or readiness for the geomorphologic process due to topography, vegetation and climate of the site. These conditions are considered as constant in the short-term timeframe (day). The phase "variable disposition" is the temporally alternating disposition for dangerous processes resulting from the seasonal and diurnal variability of meteorological parameters. The phase "variable disposition" varies within a timeframe of days or hours. The "triggering event" finally forms the strain to the system with a basic and high variable disposition for dangerous processes and might cause a release of the process. This process phase varies within a timeframe of a few hours or seconds. In forecasting dangerous processes, the consideration of these different process phases is important, because their indicators and 
parameters depend on the time delay before the triggering of the process. If the reaction time needed for the evacuation of endangered areas is half a day, the triggering event can not be considered because the environmental conditions related to this process phase change faster than the needed time for evacuation of potentially endangered areas. Thus, forecasting e.g. the release of wet snow avalanches one day before a triggering event, the daily variable release disposition has to be modelled. Because of rapidly changing environmental conditions related to the triggering event (hours or seconds), this process phase can not be considered in the considered timeframe (one day). In this study, it was aimed to model the daily variability of the process phase "variable disposition" for the release of wet snow avalanches as the basis of the estimation of the hazard potential.

The damage potential on road networks is defined by the number of potentially endangered persons and is subsequently derived from the traffic density, as outlined in Wilhelm (1997) and Borter (1999). The daily traffic density, and, as a consequence, the variable damage potential, is subject to considerable variations, particularly in regions affected by tourism. The method for analysing risk in a short-term timeframe, as outlined in Zischg et al. (2005), had to be adapted to the process characteristics of wet snow avalanches.

The method was developed and tested in the avalancheprone study area of the Sulden road between the municipalities of Prad and Sulden, Sulden Valley, Autonomous Province of Bozen, Italy (Fig. 1). This road serves as access road to the main ski area of the region and is therefore of particular importance for winter tourism. The road segment is $20 \mathrm{~km}$ long and is endangered by 22 avalanche paths which reached the road at least once during the 25 years of observation by the avalanche incident registry of the Autonomous Province of Bozen-South Tyrol. Due to the construction of permanent protection measures during the 1970s and 1980s, 17 avalanches in twelve paths remained perilous and threatened the road in 2004 (Fig. 1).

\section{Method}

The procedure of modelling the behaviour of the system "wet snow avalanche prone road" is based on three modules: The first module computes the variable disposition for the release of wet snow avalanches. The second component of the procedure selects the avalanche paths that pose a potential hazard to the road under current environmental conditions and deduces an avalanche hazard index map. Based on this dynamically created hazard index map, the third module calculates the number of potentially affected persons on the road. A user interface facilitates the management of data input, the amplification of the rule base, the inference method and shows the results in the form of alphanumerical data and maps. The required methodological procedures used in this study are described in the following sections.

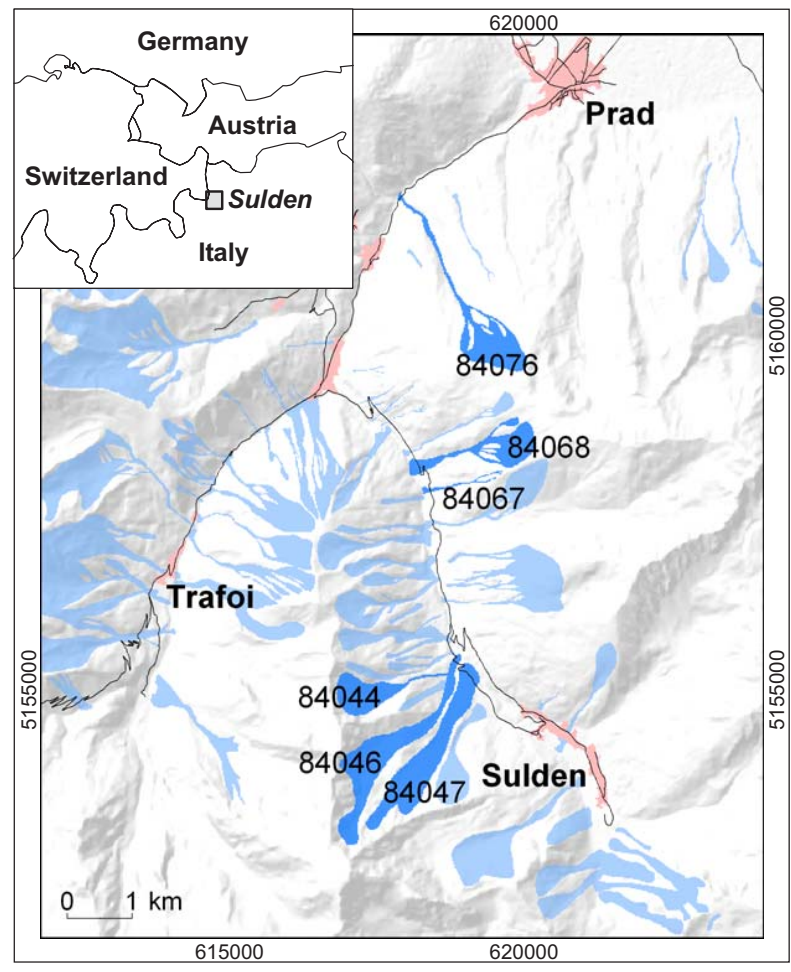

Fig. 1. Study area Sulden Road, Ortles Alps, South Tyrol, Italy. In slight blue, the dataset of the avalanche observation database of the Autonomous Province of Bolzano - South Tyrol is illustrated. In deep blue, the avalanches are pointed out that in the observation period (1980-2000) reached once the Sulden road as wet snow avalanche. The labels indicate the official ID of the avalanche database. Source: Autonome Provinz BozenSüdtirol/Lawinenwarndienst (2003). Coordinate system: UTM N32 ETRS89.

\subsection{Modelling the variable disposition for the release of wet snow avalanches}

The release probability of dry snow avalanches in the longterm timeframe (for example in 30 years), is deduced from the recurrence interval of a certain amount of new snow in three days within the considered timeframe. It is assumed that the occurrence probability of the avalanche event equals the occurrence probability of the snowfall event (Wilhelm, 1997). This approach has been adapted for the determination of the avalanche release probability in the short-term timeframe by Zischg et al. (2005). In this approach, the avalanche occurrence probability in the short-term timeframe is determined on the basis of a statistical correlation to the fresh snow accumulation in three days. This simplified method is not adaptable for the purpose of modeling the release probability of wet snow avalanches, because there is not a single significant parameter for the triggering of wet snow avalanches such as it is the strain of a new snow layer to the older snow pack (McClung and Schaerer, 1993). The variable release disposition of wet snow avalanches depends on 
a combination of interdependent environmental parameters. Besides the loading by new precipitation (snow or rain), wet snow avalanches can be triggered by changes in strength of a buried weak layer due to water, or by water lubrication of a sliding surface (McClung and Schaerer, 1993). The moisture penetration in a snow pack may be a result of snow melting due to solar radiation, due to latent heat transfer or a rainfall event. The increase of moisture in the snow pack results in a decline of the stability caused by a decrease of friction and cohesion. Frequently, wet slab avalanche events occur during rainfall periods in wintertime or during the first period of snow melting in spring (LaChapelle, 1977). One indicator for a high disposition for wet snow avalanches is an isothermal snow pack on southern exposed hill slopes (Armstrong and Yves, 1976). After the snow pack is becoming isothermal, the content of free water in the snow cover increases during the following days while the strength of the snow cover decreases. Isothermal conditions can be observed 1015 days prior the first significant wet snow avalanche activity in spring (Armstrong and Yves, 1976). The decreasing cohesiveness is reflected by decreasing ram hardness. After a period of isothermal conditions, during days with a mean daily air temperature above $0^{\circ} \mathrm{C}$ an increased wet slab avalanche activity can be observed. On the basis of these indicators, days with an increased avalanche activity could be predicted. But the exact point in time, when an avalanche is triggered, can not be predicted on a regional level, due to the complex interaction between topographical, meteorological and nivological parameters (Armstrong and Yves, 1976).

The aim of this procedure was to model the variable disposition for wet snow avalanches during the winter on a regional scale. The procedure was developed based on the example of the Sulden road, but the spatial resolution of the release disposition is defined by the regional scale. In this paper, the term "wet snow avalanche" was used for wet slab avalanches, which are not triggered by the loading of new snow. Loose snow avalanches were not considered. The conditions leading to the triggering of large wet snow avalanches capable of reaching the road have been evaluated on the basis of measurements or observations of different environmental parameters. The limits of the determination of the wet snow avalanche release probability on the basis of a statistical correlation become clearly obvious due to the insufficient statistical basis. Moreover the computation method of the daily release probability is subject to significant uncertainties (Zischg et al., 2005). A possibility for the simulation of the varying release disposition of an avalanche is the fuzzy logic approach. This allows statistically non-significant parameters as well as the preconditions of the system to be taken into consideration. Furthermore, quantitative and qualitative variables can be combined mathematically and the uncertainties in the data basis can be dealt with. While dealing with natural hazards, however, uncertainty is part of most approaches (Barbolini et al., 2002; Bell and Glade, 2004: Zischg et al., 2004).

Uncertainty can be classified into three main types (Zimmermann, 1993): First, uncertainty is based on the lack of knowledge of the future state of a system. This type of uncertainty is subject to randomness (stochastic uncertainty). Second, uncertainty arises due the lack of information about the system behaviour (vagueness, ambiguity, fuzziness). Third, uncertainty is based on inexactness of measurements (impreciseness, fuzziness). Probability theory provides methods to compute the first nature of uncertainty related to randomness, while fuzzy logic provides mathematical methods to compute the second group of uncertainty (impreciseness). In comparison to the results of stochastic events, which can either be true or false; results of fuzzy events can be quantified by a degree of truth or a membership to a set (Zadeh, 1965). Fuzzy logic is a way of combining quantitative and qualitative variables, which belong to a specific fuzzy set (Zadeh, 1975). Elements can be a partially member of a specific set and at the same time have a partially membership of the complement set (Zadeh, 1965). This kind of element representation leads to a possibility for dealing with vague information and imprecise input data. Integrated into an expert system, fuzzy logic provides an opportunity for the representation of imprecise and linguistic variables in the computing procedure and the representation of the expert knowledge within a fuzzy logic rule base.

The knowledge base in this procedure is based on the supra-regional expert knowledge accessible by the scientific literature and the knowledge about the specific regional properties of the system behaviour. The scientific background, summarized in the former section, is incorporated in a simplified way into the rule base as shown in Table 1. Only variables for which a continuous dataset exists are represented in the rule base.

The supra-regional expert knowledge was adapted to the specific conditions and the available dataset describing the daily variability of the system behaviour. For the implementation of the adapted knowledge into the fuzzy logic rule base, observation data from the snow measurement station in Weissbrunn (1900 m a.s.1.), $20 \mathrm{~km}$ south-east of the study area, was used. Since December 1983, snow heights, the amount of new snow, the snow and air temperature, and the density of the snow pack according to the guidelines of the Interregional Association for Snow and Avalanches in Italy AINEVA were measured at this station (Autonome Provinz Bozen-Südtirol/Lawinenwarndienst 1983, 1997). The environmental parameters recorded from 1983 to 2000 were compared with the observed and documented avalanche events in the study area. For those avalanches that hit the road section, the temperature of the snow cover in a depth of $30 \mathrm{~cm}$, the amount of precipitation (rain), the mean daily air temperature, the daily minimum of the air temperature, and the moisture in the snow cover, were analysed and classified into fuzzy sets. For every fuzzy set, the membership functions were determined on the basis of statistical analyses of a sample of the dataset (Zischg, 2004). The membership functions of the variables taken into consideration in the computing process are illustrated in Fig. 2. The moisture of the snow pack and the output variable "wet snow avalanche release disposition" were considered as linguistic 
Table 1. Rule base of the expert system.

\begin{tabular}{|c|c|c|c|}
\hline Rule no. & IF-clause & THEN-clause & degree of truth \\
\hline 1 & $\begin{array}{l}\text { IF "snow temperature" IS “warm" AND "mean air temperature" } \\
\text { IS "warm" AND "minimum air temperature" IS "warm" AND } \\
\text { "moisture" IS "yes" }\end{array}$ & $\begin{array}{l}\text { THEN "variable release disposition" IS } \\
\text { "avalanches expected" }\end{array}$ & 1 \\
\hline 2 & $\begin{array}{l}\text { IF "snow temperature" IS “warm" AND "mean air temperature" } \\
\text { IS "warm" AND "minimum air temperature" IS "cold" AND } \\
\text { "moisture" IS "yes" }\end{array}$ & $\begin{array}{l}\text { THEN "variable release disposition" IS } \\
\text { "avalanches expected" }\end{array}$ & 1 \\
\hline 3 & $\begin{array}{l}\text { IF "snow temperature" IS “warm" AND "mean air temperature" } \\
\text { IS "cold" AND "minimum air temperature" IS "warm" AND } \\
\text { "moisture" IS "yes" }\end{array}$ & $\begin{array}{l}\text { THEN "variable release disposition" IS } \\
\text { "avalanches expected" }\end{array}$ & 1 \\
\hline 4 & IF “snow temperature” IS “medium” AND „,moisture” IS “yes” & $\begin{array}{l}\text { THEN "variable release disposition" IS } \\
\text { "no avalanches expected" }\end{array}$ & 1 \\
\hline 5 & IF "snow temperature" IS “cold" AND "moisture" IS “yes" & $\begin{array}{l}\text { THEN "variable release disposition" IS } \\
\text { "no avalanches expected" }\end{array}$ & 1 \\
\hline 6 & IF “moisture” IS “no” & $\begin{array}{l}\text { THEN "variable release disposition" IS } \\
\text { "no avalanches expected" }\end{array}$ & 1 \\
\hline 7 & $\begin{array}{l}\text { IF "snow temperature” IS “warm” AND “mean air temperature” } \\
\text { IS “warm” AND “minimum air temperature” IS “cold” AND } \\
\text { „moisture” IS “yes” }\end{array}$ & $\begin{array}{l}\text { THEN "variable release disposition" IS } \\
\text { "no avalanches expected" }\end{array}$ & 0.8 \\
\hline 8 & $\begin{array}{l}\text { IF "snow temperature" IS "warm" AND "mean air temperature" } \\
\text { IS "cold" AND "minimum air temperature" IS "cold" AND } \\
\text { "moisture" IS "yes" }\end{array}$ & $\begin{array}{l}\text { THEN "variable release disposition" IS } \\
\text { "no avalanches expected" }\end{array}$ & 0.8 \\
\hline 9 & $\begin{array}{l}\text { IF "snow temperature" IS "medium" AND "mean air tempera- } \\
\text { ture" IS "warm" AND "minimum air temperature" IS "warm" } \\
\text { AND "moisture" IS “yes" }\end{array}$ & $\begin{array}{l}\text { THEN "variable release disposition" IS } \\
\text { "no avalanches expected" }\end{array}$ & 1 \\
\hline 10 & $\begin{array}{l}\text { IF "snow temperature" IS "cold" AND "mean air temperature" } \\
\text { IS "warm" AND "minimum air temperature" IS "warm" AND } \\
\text { "moisture" IS “yes" }\end{array}$ & $\begin{array}{l}\text { THEN "variable release disposition" IS } \\
\text { "no avalanches expected" }\end{array}$ & 1 \\
\hline
\end{tabular}
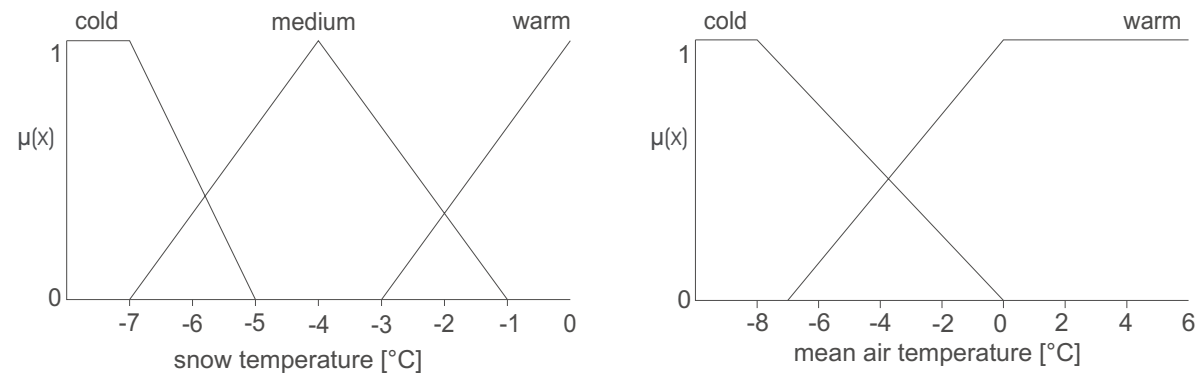

Fig. 2. Implemented membership functions of the environmental parameters.

variables after Zadeh (1975) and described by a singleton. After Cox (1999), the rules were weighted according to their importance by means of a degree of confidence into the rule within the range $(0 \ldots 1)$. This degree of confidence into the rule forms the maximally possible degree of applicability of a rule to a specific environmental condition. The quantitative variables of the input data had been fuzzyfied by means of the membership functions shown in Fig. 2. Qualitative variables were directly entered into the system as linguistic variables. The inference procedure computed the input data forward-chained, applying the rules of the knowledge base to this data. To the given specifications, the inference engine looks for rules, which are suitable and applicable to the situation described by the input data. One inference step consists in the evaluation of a rule. Each condition in the IF-clause of a rule must be aggregated to the degree of applicability of the whole IF-clause (Zimmermann, 1993). In the aggregation step of the inference procedure the logical ANDoperator was applied. This operator determines the minimum of the fuzzy membership degrees of all variables in the IFclause by using the minimum function. In the implication step of the inference procedure the MIN-operator was used. In this step, the membership degree of the output variable describing the conclusion of a rule was computed on the basis 
Table 2. Subset of wet snow avalanche paths that reached the road once during the observation period (1980-2000) and related topographic parameters of their starting zones. Additonally, an overview of the parameters used in the set of calculations of the number of potentially affected persons by avalanches on the road is given (cf. Zischg et al., 2005).

\begin{tabular}{cccccccccc}
\hline $\begin{array}{c}\text { Avalanche } \\
\text { path no. }\end{array}$ & $\begin{array}{c}\text { Min. altitude } \\
\text { level of } \\
\text { starting zone } \\
\text { (m a.s.l.) }\end{array}$ & $\begin{array}{c}\text { Max. altitude } \\
\text { level of } \\
\text { starting zone } \\
(\mathrm{m} \text { a.s.l.) }\end{array}$ & $\begin{array}{c}\text { Min. snow } \\
\text { height of } \\
\text { starting zone } \\
(\mathrm{cm})\end{array}$ & $\begin{array}{c}g \\
(\mathrm{~km})\end{array}$ & $\begin{array}{c}v \\
(\mathrm{~km} / \mathrm{h})\end{array}$ & $\begin{array}{c}\lambda \\
(\mathrm{l})\end{array}$ & $\begin{array}{c}\text { WDT } \\
(\text { cars/ } \\
\text { day) }\end{array}$ & $\begin{array}{c}\beta \\
\text { (pers./ } \\
\text { car) }\end{array}$ & $\begin{array}{c}\text { mean of } \\
\mu(\text { sunny } \\
\text { hill slopes) } \\
\text { on 21 March }\end{array}$ \\
\hline 84076 & 2200 & 2560 & 50 & 0.275 & 60 & 0.18 & 1300 & 2 & 0.01 \\
84068 & 2190 & 2810 & 50 & 0.125 & 30 & 0.40 & 951 & 2 & 0.17 \\
84067 & 2320 & 2410 & 50 & 0.060 & 50 & 0.18 & 951 & 2 & 0.1 \\
84044 & 2450 & 2740 & 50 & 0.035 & 30 & 0.40 & 951 & 2 & 0.84 \\
84046 & 2450 & 3180 & 50 & 0.125 & 30 & 0.40 & 951 & 2 & 0.56 \\
84047 & 2380 & 3220 & 50 & 0.400 & 35 & 0.40 & 951 & 2 & 0.1 \\
\hline
\end{tabular}

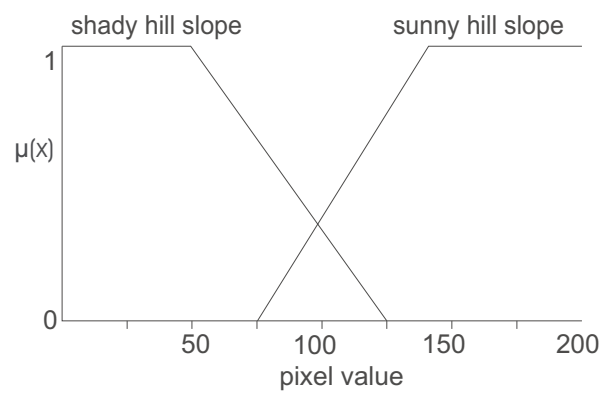

Fig. 3. Fuzzy membership function for the terms of the variable "exposition to the sun".

of the degree of applicability of the IF-clause (Bothe, 1993). The upper limit of the membership degree of the conclusion term of the rule was given by the degree of confidence into the rule. If more rules with the same conclusion term were existent, the membership degrees of the conclusion terms of all applicable rules had been accumulated to one membership degree of the final conclusion (Zimmermann, 1993). The implemented operator for the accumulation procedure of the inference engine was the maximum operator. The result of the inference procedure was the accumulated membership degree to each conclusion term of the variable "wet snow avalanche release disposition" in the rule base. For the rule base exemplarily illustrated in Table 1, the result was the membership degree of the conclusion terms "avalanches expected" or "no avalanches expected". This value represents the membership of a specific day characterised by the related combination of environmental parameters to the fuzzy sets "days with expected wet snow avalanche activity" or "days with no avalanche activity expected". The membership degree of the fuzzy set "days with expected wet snow avalanche activity" can be equated to a degree of compatibility to the concept "wet snow avalanche release disposition".
2.2 Spatial interpolation of the release disposition for wet snow avalanches

In the second module of the procedure, avalanche paths that pose a potential hazard to the road under current environmental conditions were determined. First, the avalanche observation database was analysed and from all avalanche paths a subset of relevant avalanches was created. Those avalanches that reached the road as wet snow avalanche once during the observation period (1980-2000) were selected. Furthermore, the topographic parameters of the starting zone of these avalanche paths were determined (see Table 2).

Second, from this subset those days with avalanches that feature a high release disposition were determined. In this step, the result of the modelled disposition for the release of wet snow avalanches was spatially interpolated. In combination with the modelled release disposition, additional information in the avalanche bulletin describing the spatial characteristics of possible hazardous processes was used to determine avalanche paths for the road. During potentially hazardous situations, the avalanche bulletin gives information about the following topographical factors: The information about the spatial distribution of the height and the extent of the snow cover is differentiated by altitude and exposition. Information about the moisture penetration of the snow cover is distinguished between altitude levels and exposition classes (sunny or shady hillside situations). These topographic parameters were spatially interpolated based on GIS-operations. The parameter "exposition of the hill slope to the sun" was classified into two terms, either expressed as "sunny" or "shady hill slopes". The hillshade-function implemented in the GIS was used for the calculation and is based on the digital terrain model with a spatial resolution of $20 \mathrm{~m}$. The parameters required for this calculation, the azimuth and the altitude, describe the position and altitude of the sun specified for the considered day and the time of day.

For every day, this procedure was repeated, using the position of the sun depending on the geographic location and the calendar day and the altitude of the sun on midday. The result of the hillshade-function is a raster grid with values in 


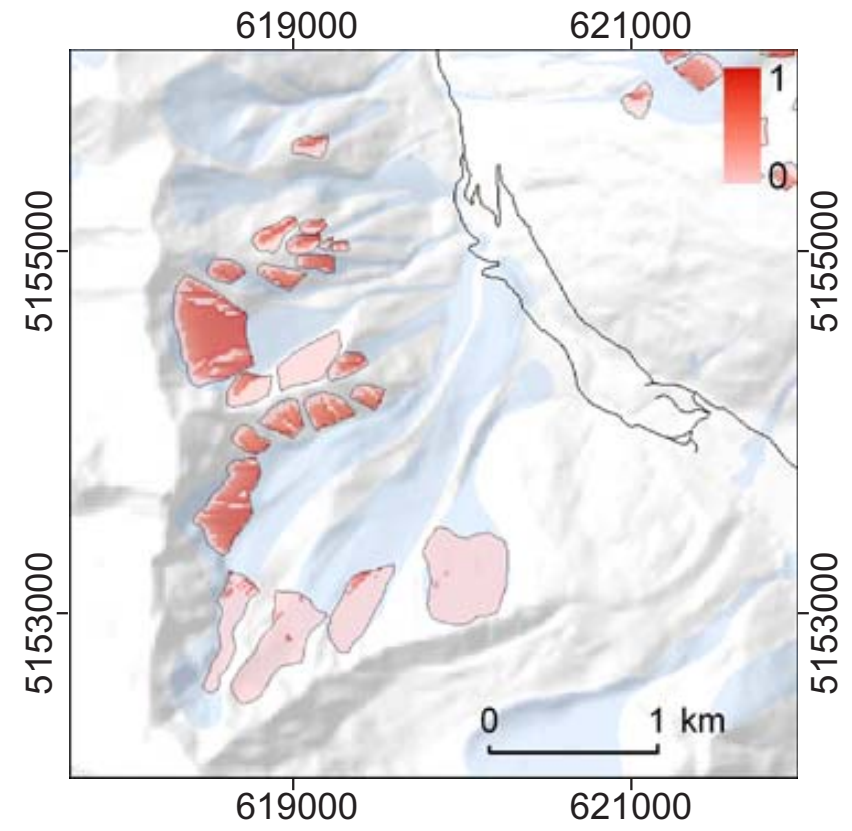

Fig. 4. Fuzzy membership degree of the disposition for the release of wet snow avalanche on sunny hillsides below $2800 \mathrm{~m}$. Situation on 2 May 2001. Coordinate system: UTM N32 ETRS89.

the range between 0 and 255. This raster grid was converted into two raster-based information layers using the membership function illustrated in Fig. 3. For each starting zone of an avalanche path, the mean of the raster values was calculated (see Fig. 4). The mean of the raster values of the information layers "sunny hill slopes" or "shady hill slopes" was compared with the linguistic variable of the "hill slope position" in the avalanche bulletin. If the bulletin indicated a high release disposition of wet snow avalanches on "sunny hill slopes", a subset of avalanche starting zones exceeding a membership degree of 0.5 of the term "sunny hill slopes" was created. From this subset, those avalanches were selected, that met the conditions for the minimum of a snow height about $50 \mathrm{~cm}$ and the altitude level of the moisture penetration of the snow cover indicated by the avalanche bulletin. For these avalanche starting zones that fulfil the topographic requirements indicated in the avalanche bulletin, the release of an avalanche was assumed. The avalanche release disposition was quantified by the applied rule base for the term "avalanches expected". If no avalanches were selected due to topographic restrictions, the membership of the term "avalanches expected" was set to 0 . If the avalanche bulletin indicated only a release disposition for hill slopes exposed to the sun, the release disposition is determined by the minimum of the membership value of the term "avalanches expected" and the maximum of the membership values of the term "sunny hill slope" of all selected avalanche starting zones. From the GIS-dataset of the avalanche paths, the geographic data of the potentially hazardous avalanche paths was selected and mapped out (see Fig. 5). It was assumed, that a) the selected avalanches trigger with the maximal ex-

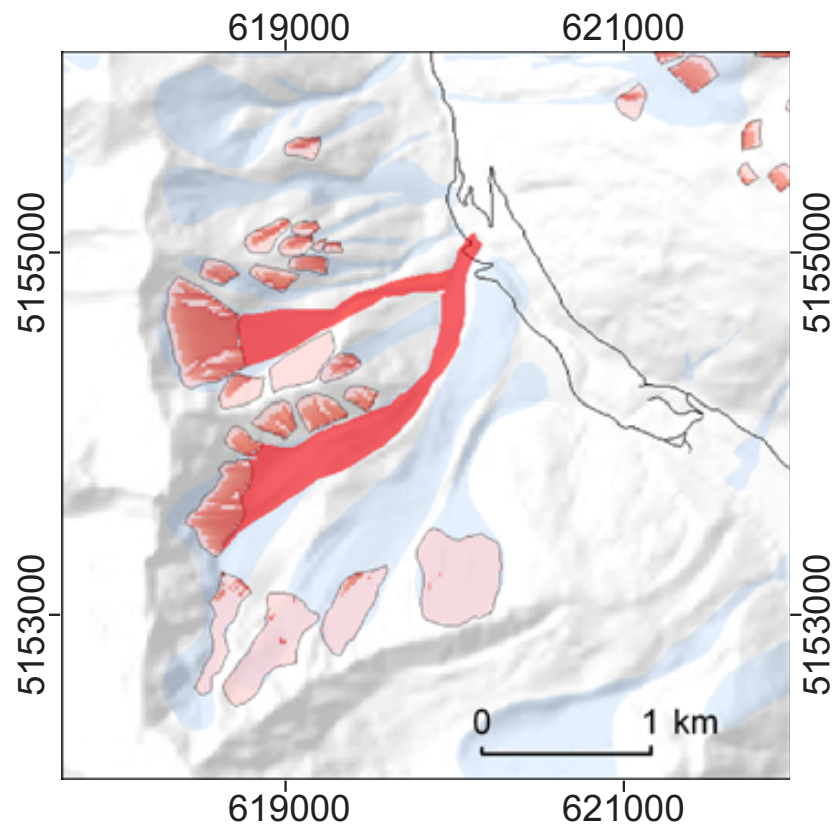

Fig. 5. Computed subset of the avalanche paths (red colour) threatening the road due to the environmental conditions on 2 May 2001. The universe of all avalanche paths is mapped in slight blue. Coordinate system: UTM N32 ETRS89.

tent of the release area as indicated in the avalanche observation database; b) the selected avalanches reach the road; and c) the avalanche cross the road with an average width as indicated in the avalanche observation database. This dynamically created hazard index map formed the basis for the calculation of the damage potential on the road. Input for the determination of the number of potentially affected persons is the mean width of the selected avalanche paths crossing the road.

\subsection{Calculation of the variable damage potential on the road}

To calculate the possible consequences of the hazard potential computed by the procedure described in the previous sections, the number of persons at risk was estimated on the basis of the dynamically created hazard index map and the traffic volume (WDT). The mean daily traffic density on the Sulden road is 951 vehicles per day (Autonome Provinz Bozen-Südtirol/ASTAT 2002) and reaches a maximum of 2700 vehicles per day. Automatic traffic counts for the Sulden road have been recorded on a daily resolution only since 2002 (Autonome Provinz Bozen-Südtirol/ASTAT 2004). As the road serves as main access road to the ski area of the region, the traffic density is significantly higher during weekends and holidays than on weekdays. From the traffic observation's database (Autonome Provinz BozenSüdtirol/ASTAT 2004) results, that the traffic density is $30 \%$ above the average during weekends and $9 \%$ below the average during weekdays. Thus, the traffic density for the winter 2000/2001 was modelled adding $30 \%$ of the mean daily 


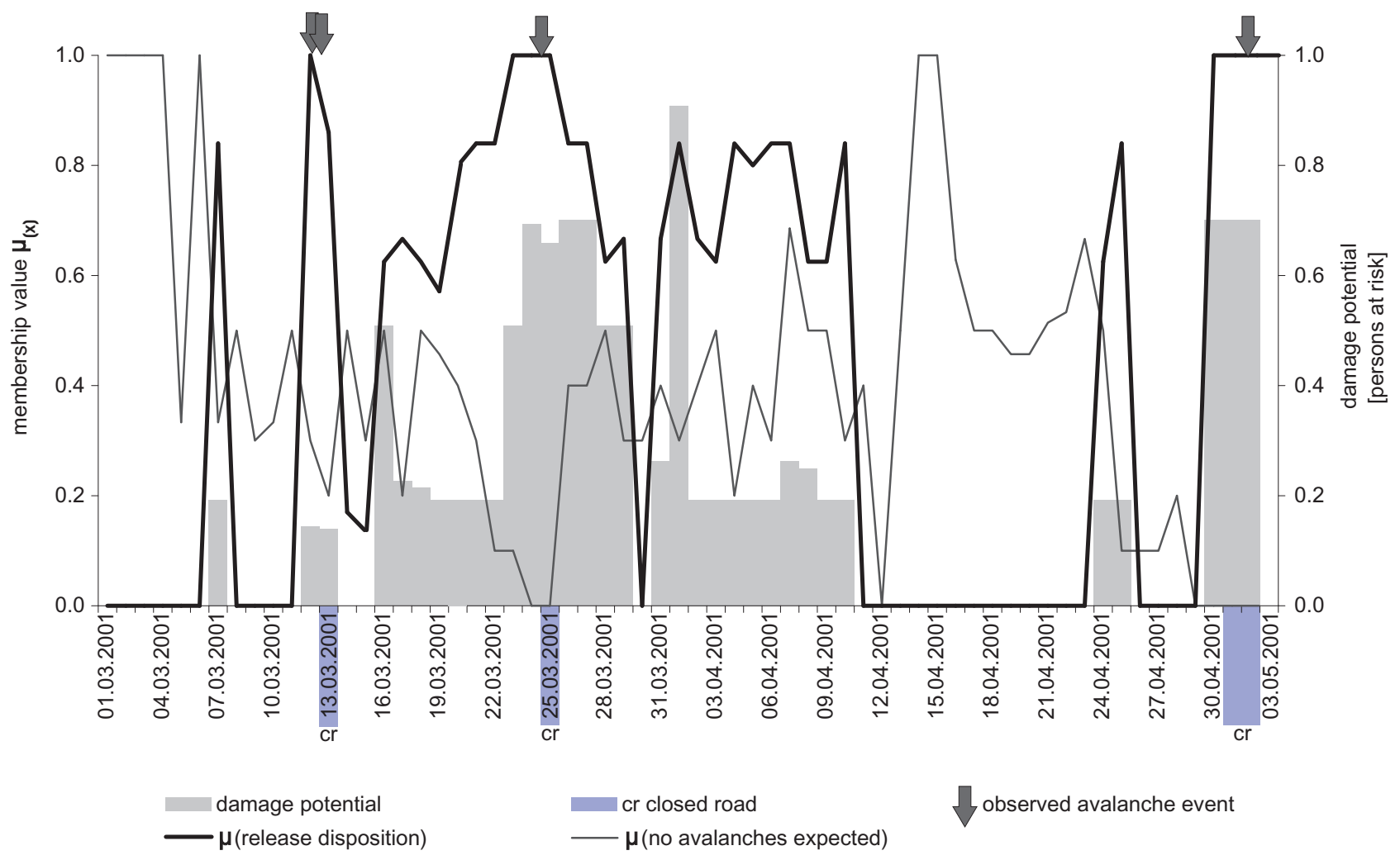

Fig. 6. Computed results of the rule base for the estimation of the release disposition. The bolt line shows the "release disposition for wet snow avalanches". The slight line shows the result of the rules for the term "no avalanches expected". The value of the datasets shows the membership of the parameter combination of the day to the set of days with or respective with no avalanches expected. The grey bars show the number of persons potentially affected by wet snow avalanches on the road. The blue bars show the days, on which the road was closed due to an increased avalanche hazard. The arrows show observed avalanches events in the study area.

traffic density during weekends and reducing the mean value about $9 \%$ on weekdays.

To calculate the short-term variable number of persons at risk $(d p)$, parameters such as the mean width of avalanches crossing the road $(g)$, the average speed of cars $(v)$, the mean number of passengers per $\operatorname{car}(\beta)$ and the probability of death in vehicles $(\lambda)$ were defined using the method of Wilhelm (1997). The calculated damage potential for every single avalanche path was subsequently summed up for the respective road section (Eq. 1). As a result, the total number of persons at risk for the observed period (day) for the whole road segment was obtained, as shown by Zischg et al. (2005).

$d p=\frac{W D T \cdot \beta}{24 h} \cdot \sum_{i=1}^{n} \frac{g_{i}}{v_{i}} \cdot \lambda_{i} \quad i=1,2 \ldots n$ avalanche paths

The results show the number of persons potentially affected by wet snow avalanches on the road due to the current environmental condition of the considered day. The membership degree of the term "avalanches expected" was interpreted as a possibility measure after Zadeh (1978) that describes the possibility of the occurrence of an event. This measure quantifies the possibility that the computed number of fatalities will occur.

\section{Results}

Based on the procedures described in the former sections and the parameters described in Table 3 , the temporal variability of the release disposition for wet snow avalanches and the damage potential was determined on the basis of the input parameters weekday (date), moisture penetration of the snow pack (moist. penetr.), minimum of the daily air temperature (TminC), the mean of the daily air temperature, snow height, temperature of the snow pack in a depth of $30 \mathrm{~cm}$ (TH-0.3C), the altitude level until the snow pack is considered as wet (moist. alt. level), and the hill slope position (hill slope pos.).

In Fig. 6, the results of the inference for the estimation of the release disposition are shown. The values of the datasets describe the membership of the considered day, characterised by its parameter combination, to the set of days with ( $\mu$ (av. exp.)) or with no avalanches expected ( $\mu$ (no av. exp.)) in the period from 1 March 2001 to 3 May 2001. For this period, the necessary input data, the avalanche bulletins, documented avalanche events in the study area and documented closures of the Sulden road due to wet snow avalanche hazard were available. On the basis of the latter datasets, the computed result of the procedure could be verified. In Fig. 6, a high temporal variability of the avalanche release disposition is 
Table 3. Input parameters of the procedure and computed results.

\begin{tabular}{|c|c|c|c|c|c|c|c|c|c|c|c|c|c|}
\hline date & $\begin{array}{l}\text { moist. } \\
\text { penetr. }\end{array}$ & $\begin{array}{c}T \\
\min \mathrm{C} \\
\left({ }^{\circ} \mathrm{C}\right)\end{array}$ & $\begin{array}{c}T \\
\text { mean } \mathrm{C} \\
\left({ }^{\circ} \mathrm{C}\right)\end{array}$ & $\begin{array}{l}\text { snow } \\
\text { height } \\
(\mathrm{cm})\end{array}$ & $\begin{array}{c}\mathrm{TH}-0.3 \mathrm{C} \\
\left({ }^{\circ} \mathrm{C}\right)\end{array}$ & $\begin{array}{c}\mu \\
\text { (av. } \\
\text { exp.) }\end{array}$ & $\begin{array}{c}\mu \\
\text { (no av. } \\
\text { exp.) }\end{array}$ & $\begin{array}{c}\text { moist. alt. } \\
\text { level } \\
\text { (m a.s.1.) }\end{array}$ & $\begin{array}{l}\text { hill } \\
\text { slope } \\
\text { pos. }\end{array}$ & $\begin{array}{c}\mu \\
\text { (rel. } \\
\text { disp.) }\end{array}$ & $\begin{array}{c}\mathrm{dp} \\
\text { (persons) }\end{array}$ & $\begin{array}{c}\text { closed } \\
\text { road }\end{array}$ & $\begin{array}{l}\text { Wet snow } \\
\text { aval. obs. }\end{array}$ \\
\hline 01.03 .2001 & & -12 & -10.5 & 162 & -7 & 0 & 1 & & & 0.00 & 0.00 & & 0 \\
\hline 02.03.2001 & & -11 & -10 & 163 & & 0 & 1 & & & 0.00 & 0.00 & & 0 \\
\hline 03.03 .2001 & & -17 & -10.5 & 175 & -6 & 0 & 1 & & & 0.00 & 0.00 & & 0 \\
\hline 04.03 .2001 & & -7 & -3.5 & 173 & -4 & 0 & 1 & & & 0.00 & 0.00 & & 0 \\
\hline 05.03.2001 & yes & -3 & 0 & 182 & -2 & 0.333 & 0.333 & 2000 & & 0.00 & 0.00 & & 0 \\
\hline 06.03 .2001 & yes & -6 & 0 & 171 & -4 & 0 & 1 & & & 0.00 & 0.00 & & 0 \\
\hline 07.03.2001 & yes & -6 & -1 & 168 & -2 & 0.333 & 0.333 & 2600 & & 0.84 & 0.19 & & 0 \\
\hline 08.03.2001 & yes & -5 & 0 & 165 & -1 & 0.625 & 0.5 & & & 0.00 & 0.00 & & 0 \\
\hline 09.03 .2001 & yes & -3 & -1 & 180 & -1 & 0.666 & 0.3 & 2000 & & 0.00 & 0.00 & & 0 \\
\hline 10.03 .2001 & yes & -5 & -2 & 175 & -2 & 0.333 & 0.333 & 2000 & & 0.00 & 0.00 & & 0 \\
\hline 11.03 .2001 & yes & -5 & -2 & 172 & -1 & 0.625 & 0.5 & & & 0.00 & 0.00 & & 0 \\
\hline 12.03 .2001 & yes & -3 & 1 & 169 & 0 & 1 & 0.3 & 2200 & & 1.00 & 0.14 & & 1 \\
\hline 13.03 .2001 & yes & -2 & -1 & 195 & 0 & 0.857 & 0.2 & 2200 & & 0.86 & 0.14 & yes & 1 \\
\hline 14.03 .2001 & yes & -5 & -0.5 & 189 & 0 & 0.625 & 0.5 & 2200 & sunny & 0.17 & 0.00 & & 0 \\
\hline 15.03 .2001 & yes & -3 & 0 & 176 & -1 & 0.666 & 0.3 & 2200 & & 0.17 & 0.00 & & 0 \\
\hline 16.03 .2001 & yes & -5 & 0 & 171 & 0 & 0.625 & 0.5 & 2400 & & 0.63 & 0.51 & & 0 \\
\hline 17.03.2001 & yes & -2 & 1.5 & 169 & -1 & 0.666 & 0.2 & 2300 & & 0.67 & 0.23 & & 0 \\
\hline 18.03.2001 & yes & -5 & -2.5 & 175 & 0 & 0.625 & 0.5 & 2300 & & 0.63 & 0.22 & & 0 \\
\hline 19.03.2001 & yes & -5 & -3 & 167 & 0 & 0.571 & 0.457 & 2600 & sunny & 0.57 & 0.19 & & 0 \\
\hline 20.03 .2001 & yes & -4 & 0 & 164 & 0 & 0.8 & 0.4 & 2600 & sunny & 0.80 & 0.19 & & 0 \\
\hline 21.03 .2001 & yes & -3 & 2 & 161 & 0 & 1 & 0.3 & 2600 & sunny & 0.84 & 0.19 & & 0 \\
\hline 22.03 .2001 & yes & -1 & 2 & 161 & 0 & 1 & 0.1 & 2600 & sunny & 0.84 & 0.19 & & 0 \\
\hline 23.03 .2001 & yes & -1 & 3.5 & 155 & 0 & 1 & 0.1 & 2400 & & 1.00 & 0.51 & & 0 \\
\hline 24.03 .2001 & yes & 0 & 4.5 & 153 & 0 & 1 & 0 & 2400 & & 1.00 & 0.69 & & 0 \\
\hline 25.03 .2001 & yes & 0 & 4 & 150 & & 1 & 0 & 2400 & & 1.00 & 0.66 & yes & 2 \\
\hline 26.03 .2001 & yes & -4 & 2.5 & 144 & 0 & 0.8 & 0.4 & 2500 & & 0.84 & 0.70 & & 0 \\
\hline 27.03.2001 & yes & -4 & 0 & 150 & 0 & 0.8 & 0.4 & 2500 & & 0.84 & 0.70 & & 0 \\
\hline 28.03 .2001 & yes & -5 & 0 & 142 & -1 & 0.625 & 0.5 & 2400 & & 0.63 & 0.51 & & 0 \\
\hline 29.03.2001 & yes & -3 & -1.5 & 146 & -1 & 0.666 & 0.3 & 2400 & & 0.67 & 0.51 & & 0 \\
\hline 30.03 .2001 & yes & -3 & -0.5 & 188 & -1 & 0.666 & 0.3 & & & 0.00 & 0.00 & & 0 \\
\hline 31.03 .2001 & yes & -4 & -2 & 190 & -1 & 0.666 & 0.4 & 2500 & sunny & 0.67 & 0.26 & & 0 \\
\hline 01.04 .2001 & yes & -3 & -1.5 & 186 & -1 & 0.666 & 0.3 & 2500 & & 0.84 & 0.91 & & 0 \\
\hline 02.04 .2001 & yes & -4 & -1 & 180 & -1 & 0.666 & 0.4 & 2500 & sunny & 0.67 & 0.19 & & 0 \\
\hline 03.04 .2001 & yes & -5 & 1.5 & 160 & 0 & 0.625 & 0.5 & 2500 & sunny & 0.63 & 0.19 & & 0 \\
\hline 04.04 .2001 & yes & -2 & 4.5 & 151 & 0 & 1 & 0.2 & 2500 & sunny & 0.84 & 0.19 & & 0 \\
\hline 05.04 .2001 & yes & -4 & 4 & 163 & 0 & 0.8 & 0.4 & 2500 & sunny & 0.80 & 0.19 & & 0 \\
\hline 06.04 .2001 & yes & -3 & 3.5 & 160 & & 1 & 0.3 & 2500 & sunny & 0.84 & 0.19 & & 0 \\
\hline 07.04.2001 & yes & -7 & -1 & 149 & 0 & 0.857143 & 0.6857144 & 2500 & sunny & 0.84 & 0.26 & & 0 \\
\hline 08.04.2001 & yes & -5 & -2.5 & 167 & 0 & 0.625 & 0.5 & 2500 & sunny & 0.63 & 0.25 & & 0 \\
\hline 09.04.2001 & yes & -5 & -1.5 & 161 & 0 & 0.625 & 0.5 & 2500 & sunny & 0.63 & 0.19 & & 0 \\
\hline 10.04 .2001 & yes & -3 & -0.5 & 157 & 0 & 0.9285715 & 0.3 & 2500 & sunny & 0.84 & 0.19 & & 0 \\
\hline 11.04 .2001 & yes & -4 & -2 & 165 & & 0.714286 & 0.4 & & & 0.00 & 0.00 & & 0 \\
\hline 12.04.2001 & yes & 0 & 1.5 & 156 & -1 & 0.666 & 0 & & & 0.00 & 0.00 & & 0 \\
\hline 13.04 .2001 & yes & -5 & -2 & 155 & 0 & 0.625 & 0.5 & & & 0.00 & 0.00 & & 0 \\
\hline 14.04 .2001 & yes & -8 & -2.5 & 150 & -4 & 0 & 1 & & & 0.00 & 0.00 & & 0 \\
\hline 15.04 .2001 & yes & -9 & -5 & 149 & -4 & 0 & 1 & & & 0.00 & 0.00 & & 0 \\
\hline 16.04 .2001 & yes & -11 & -5.5 & 148 & 0 & 0.2142865 & 0.628584 & & & 0.00 & 0.00 & & 0 \\
\hline 17.04.2001 & yes & -5 & -2 & 149 & 0 & 0.625 & 0.5 & & & 0.00 & 0.00 & & 0 \\
\hline 18.04 .2001 & yes & -5 & -2 & 148 & 0 & 0.625 & 0.5 & & & 0.00 & 0.00 & & 0 \\
\hline 19.04.2001 & yes & -8 & -4 & 150 & 0 & 0.428572 & 0.457152 & & & 0.00 & 0.00 & & 0 \\
\hline 20.04 .2001 & yes & -6 & -3 & 169 & 0 & 0.571429 & 0.4571432 & & & 0.00 & 0.00 & & 0 \\
\hline 21.04 .2001 & yes & -9 & -4.5 & 198 & -1 & 0.3571435 & 0.514296 & & & 0.00 & 0.00 & & 0 \\
\hline 22.04 .2001 & yes & -9 & -6 & 188 & -1 & 0.142858 & 0.533333333 & & & 0.00 & 0.00 & & 0 \\
\hline 23.04.2001 & yes & -5 & -2.5 & 178 & -3 & 0 & 0.666666667 & 2500 & sunny & 0.00 & 0.00 & & 0 \\
\hline 24.04 .2001 & yes & -5 & 0 & 169 & -1 & 0.625 & 0.5 & 2500 & sunny & 0.63 & 0.19 & & 0 \\
\hline 25.04 .2001 & yes & -1 & 3.5 & 161 & 0 & 1 & 0.1 & 2500 & sunny & 0.84 & 0.19 & & 0 \\
\hline 26.04 .2001 & yes & -1 & 3 & 160 & 0 & 1 & 0.1 & & & 0.00 & 0.00 & & 0 \\
\hline 27.04 .2001 & yes & -1 & 3.5 & 158 & 0 & 1 & 0.1 & & & 0.00 & 0.00 & & 0 \\
\hline 28.04 .2001 & yes & -2 & 3.5 & 153 & 0 & 1 & 0.2 & & & 0.00 & 0.00 & & 0 \\
\hline 29.04 .2001 & yes & 0 & 4 & 148 & 0 & 1 & 0 & & & 0.00 & 0.00 & & 0 \\
\hline 30.04 .2001 & yes & 0 & 3.5 & 143 & 0 & 1 & 0 & 2800 & & 1.00 & 0.70 & & 0 \\
\hline 01.05 .2001 & yes & 1 & 4.5 & 138 & 0 & 1 & 0 & 2800 & & 1.00 & 0.70 & yes & 0 \\
\hline 02.05 .2001 & yes & -1 & 4 & 129 & 0 & 1 & 0 & 2800 & & 1.00 & 0.70 & yes & 2 \\
\hline 03.05.2001 & yes & 4 & 7.5 & 118 & 0 & 1 & 0 & 2800 & & 1.00 & 0.70 & yes & 0 \\
\hline
\end{tabular}


demonstrated. The bold line shows the result of the rules for the term "avalanches expected" of the linguistic variable "release disposition for wet snow avalanches". The slight line shows the result of the rules for the term "no avalanches expected". The grey bars illustrate the computed number of persons at risk. The slight blue bars at the bottom of the figure point out the days when the road has been closed due to an elevated hazard level. On the days of the road closure, the procedure calculated a high release disposition (term "avalanches expected"). On these days, the calculated membership values for the term "no avalanches expected" were relatively low $(<0.2)$. Thus, the difference between the concurrent rules representing the two terms was significant. The avalanche bulletin indicated an avalanche hazard level of 3 on 12 March and 4 on 13 March. On 12 March, an avalanche event in avalanche path no. 84052 occurred, but this avalanche path normally do not affect the Sulden road. In the morning of 13 March, the road had been closed due to an avalanche event in avalanche path no. 84068 . The road was re-opened after the artificial release of the starting zones that had not been triggered naturally. The procedure computed membership values of 1.0 (12 March) and 0.86 (13 March) to the term "avalanches expected" and a membership value of 0.2 to the term "no avalanches expected". Furthermore, a damage potential of 0.14 persons at risk was calculated on 13 March. From 23 to 25 March, a membership degree of 1.0 to the term "wet snow avalanches expected" and a membership degree between 0.0 and 0.1 to the term "no avalanches expected" were calculated. On these days, the avalanche bulletin indicated an avalanche hazard level of 3. The damage potential was quantified as a value up to 0.69 potentially affected persons. In the evening of 25 March, the road was closed due to an elevated hazard level. An avalanche in the avalanche path no. 84037 occurred and reached the Sulden River. In the avalanche path no. 84067, an avalanche occurred and stopped at a distance of $2 \mathrm{~m}$ from the road. Another elevated release disposition was computed from 30 April to 3 May. On 2 May, the avalanche bulletin predicted an avalanche hazard level of 4 at noon. On this day, avalanches in the avalanche paths no. 84044 and 84068 occurred. After the avalanche event in avalanche path no. 84068 , the starting zones that had not been triggered, were released artificially. The road has been closed from 1 until 3 May. For these days, a damage potential of 0.7 potentially affected persons was calculated. A relatively high release disposition for wet snow avalanches (0.8 but not 1.0) was computed by the procedure on the days 7 March, 1 April, and 4-7 April. For these days, relatively high membership values to the term "no avalanches expected" ( $>0.3$ ) were calculated. Thus, the difference between the concurrent rules representing the two terms was not significant. In this case, the result of the reasoning procedure reports a considerable ambiguity in the rule base. On 7 March, a small wet snow avalanche occurred in the Stelvio Valley, outside of the study area. On the other days, no avalanches occurred. On 25 April, the procedure computed a high release disposition (0.8), and a low membership value for the term "no avalanches expected".
During this day, no avalanches were observed. In this case, the release disposition was computed as relatively high, but due to the absence of a triggering event, no avalanches occurred.

\section{Conclusions}

The validation of the procedure using data from the winter season of 2000/2001 showed that the system behaviour of wet snow avalanches can be approximately modelled with the use of only ten rules and six considered variables of system parameters. The application of this rule base to the available data in the study area generated plausible results. The ex-post modelled membership degree of the conclusion term "wet snow avalanches expected" as well as the membership degree of the conclusion term "no wet snow avalanches expected" represented the system behaviour well. During situations when the road was closed, the procedure computed reliable results. For these situations, high membership values $(>0.86)$ for the term "wet snow avalanches expected" and low membership values $(<0.3)$ for the term "no wet snow avalanches expected" were computed by the procedure. In the validation period, no wet snow avalanches occurred when the system computed low membership values $(\leq 0.84)$ for the term "wet snow avalanches expected". In addition to the days with observed avalanche events, a considerable difference between the membership degrees of both conclusion terms was computed during the first days in March 2001, and between 11 and 23 April 2001. On these days the membership degree of the conclusion term "wet snow avalanches expected" showed values of 0 and the membership degree of the conclusion term "no wet snow avalanches expected" showed values about 1.0 respective greater than 0.5 (see Table 3 ). On other days in the considered period, the membership degrees of both conclusion terms did not represent completely complements of each other. Neither for the conclusion term "wet snow avalanches expected" nor for the conclusion term "no wet snow avalanches expected" no explicit values of 1.0 or 0 were calculated. For these situations, the incorporated rule base did not calculate unambiguous model results and considerable uncertainties in the inference procedure were pointed out. In Fig. 6, the advantages of the fuzzy set theory become obvious: A day with given environmental conditions can belong to the number of days with expected wet snow avalanches and simultaneously belong to the number of days without expected avalanches. Both statements are not contradictory because in the fuzzy set theory the mathematical axiom of the exclusive contradiction is not valid (Drösser, 1994). If the difference between the computed membership degrees of the both conclusion terms is considerably high, the reliability of the computed results can be assessed as elevated. The larger the difference between the membership degrees of both conclusion terms of the rules base, the more accurate a decision on risk management can be made. Otherwise, if both conclusion terms show a similar membership degree, the reliability of the result can be interpreted 
as limited. On these situations a lack of knowledge about the system behaviour becomes obvious. For a better assessment of these environmental conditions, the expert's knowledge represented by the rule base has to be extended.

The rule base implemented up until now only represents a simplified picture of the reality. However, assessing the time variable disposition for the release of wet snow avalanches by using the expert system approach rather than on the basis of empirically determined relationships between environmental parameters and avalanche releases as shown by Zischg et al. (2005) opens up new possibilities for modelling the system behaviour of complex non-linear processes. In the possibility of combining numeric and non-numeric data or observations, the benefits of the fuzzy set theory are highlighted. The determination of the uncertainties and the information about the reliability of the knowledge base applied to the current environmental conditions leads to a better evaluation of the computed results and the reliability of the model. Nevertheless, the triggering event of wet snow avalanches cannot be modelled by the presented approach.

Fuzzy logic based inference engines are robust (Zimmermann, 1993); they primarily react to changes in the knowledge base. The higher the number of rules and the considered variables the more meaningful is the conclusion result. Thus, in the design phase of building an expert system the focus has to be directed to the representation of the expert's knowledge. Furthermore, the applied implication and aggregation operators have significant influences on the results of the inference engine. The choice of these operators depends on the rule base and the number of variables considered in the reasoning process.

As presented in Fig. 6, the variability of damage potential due to wet snow avalanches can be estimated based on the actual environmental conditions. The computed values showed a high short-term temporal variability. This seems consistent with findings presented by Zischg et al. (2005) and Keiler et al. (2005) in the context of alpine settlements. The consideration of the temporal variability of the damage potential provide information for risk management and can thus improve the quality of decision making processes.

The input data used in the development of the procedure had been recorded at a distance of $20 \mathrm{~km}$ from the study area. Although this source of impreciseness was considered by the use of fuzzy variables, the results of the expert systems probably could be more specified and accurate using input data from a weather and snow measurement station located in the study area. The procedure was developed using only a few environmental parameters. Further research is needed particularly regarding the implementation of other parameters for the determination of the release disposition for wet snow avalanches and regarding the extension of the rule base. The consideration of more parameters is possible adding more rules and parameters in the knowledge base of the expert system. The software for the inference engine must not be adapted in the case of an extension of the knowledge base. The described method could be enhanced by including additional components such as models for a computer-aided as- sessment of snow pack stability (e.g. Lehning et al., 1999), or numerical avalanche forecasting (e.g. Brabec, 2001). Nevertheless, the approach may demonstrate the potential for the application of expert systems and fuzzy logic in the field of natural hazard monitoring and risk management.

Acknowledgements. The authors thank M. Munari, C. Oberschmied, C. Mutinelli, and H. Stuefer (Avalanche Warning Service, Autonomous Province of Bozen, South Tyrol, Italy) for providing the data.

Edited by: T. Glade

Reviewed by: R. Sailer and another referee

\section{References}

Armstrong, R. L. and Yves, J. D.: Wet Snow Avalanches. Avalanche Release and Snow Characteristics. Occasional Paper no. 19, Institute of Arctic and Alpine Research, University of Colorado, 67-81, 1976.

Autonome Provinz Bozen-Südtirol/ASTAT: Verkehrsstatistik in Südtirol 2001, Bozen, 2002.

Autonome Provinz Bozen-Südtirol/ASTAT: Online traffic database, 2004, http://www.provinz.bz.it/astat/daten_online/default.htm, 2 August 2004.

Autonome Provinz Bozen-Südtirol/Lawinenwarndienst: Schlüssel für Meteonivometrische Beobachtungen an Schneemessfeldern, Bozen, 1983.

Autonome Provinz Bozen-Südtirol/Lawinenwarndienst: Kodex für Wetter und Schnee Beobachtungen, Bozen, 1997.

Barbolini, M., Natale, L., and Savi, F.: Effects of Release Conditions Uncertainty on Avalanche, Nat. Haz., 25, 225-244, 2002.

Bell, R. and Glade, T.: Quantitative risk analysis for landslides - Examples from Bildudalur, NW-Iceland, Nat. Hazards Earth Syst. Sci., 4, 117-131, 2004,

SRef-ID: 1684-9981/nhess/2004-4-117.

Bolognesi, R.: Artificial Intelligence and Local Avalanche Forecasting: The System "AVALOG", International Emergency and Engineering Conference, Arlington VA, San Diego, California, USA, 1993, edited by: Soc. of Computer Science (S.C.S.), 113116, 1993.

Bolognesi, R., Buser, O., and Good, W.: Local avalanche forecasting in Switzerland: strategy and tools, a new approach, International Snow Science Workshop 1994, Snowbird, Utah, USA, 463-472, 1994.

Borter, P.: Risikoanalyse bei gravitativen Naturgefahren, edited by BUWAL Bundesamt für Umwelt, Wald und Landschaft, Bern, 1999.

Bothe, H. H.: Fuzzy Logic, Einführung in Theorie und Anwendungen, Berlin, Heidelberg, 1995.

Brabec, B.: Computergestützte regionale Lawinenprognose, Diss ETH/SLF No. 14232, ETH Zürich, Zürich, 2001.

Bründl, M., Etter, H.-J., Steiniger, M., Klingler, C., Rhyner, J., and Ammann, W.: IFKIS - a basis for managing avalanche risk in settlements and on roads in Switzerland, Nat. Hazards Earth Syst. Sci., 4, 257-262, 2004,

SRef-ID: 1684-9981/nhess/2004-4-257.

Buisson, L. and Charlier, C.: Avalanche starting-zone analysis by use of a knowledge-based system, Ann. Glaciol., 13, 27-30, 1989. 
Buisson, L. and Charlier, C.: Avalanche modelling and integration of expert knowledge in the ELSA system, Ann. Glaciol, 18, 123$128,1993$.

Buisson, L. and Giraud, G.: Two examples of Expert Knowledge based Systems for Avalanche Forecasting and Protection, Surv. Geophys., 16, 603-619, 1995.

Cox, E.: The fuzzy systems handbook, New York, 1999.

Drösser, C.: Fuzzy Logic, Methodische Einführung in krauses Denken, Hamburg, 1994.

Durand, Y., Giraud, G., Brun, E., Merindol, L., and Martin, E.: A computer-based system simulating snowpack structures as a tool for regional avalanche forecasting, J. Glaciol., 45, 469-484, 1999.

Jackson, P.: Introduction to Expert Systems, New York, 1999.

Keiler, M., Zischg, A., Fuchs, S., Hama, M., and Stötter, J.: Avalanche related damage potential - changes of persons and mobile values since the mid-twentieth century, Nat. Hazards Earth Syst. Sci., 5, 49-58, 2005,

SRef-ID: 1684-9981/nhess/2005-5-49.

Kienholz, H.: Early warning systems related to mountain hazards, in: Early warning systems for natural disaster reduction, edited by: Zschau, J. and Küppers, A. N., Berlin, Heidelberg, New York, 555-564, 2003.

Kleemayr, K., Moser, A., Schöll, J., and Vollsinger, S.: Lawinenprognose mit statistischen und selbstlernenden Verfahren im Projekt "NAFT", Schutz des Lebensraumes vor Hochwasser, Muren und Lawinen, Proc. Intern. Symp. Interpraevent 2000, Villach, Austria, 411-422, 2000.

LaChapelle, E. R.: Snow avalanches: a review of current research and applications, J. Glaciol., 19, 313-323, 1977.

Lehning, M., Bartelt, P., Brown, B., Russi, T., Stockli, U., and Zimmerli, M.: SNOWPACK model calculations for avalanche warning based upon a new network of weather and snow stations, Cold Reg. Sc., 30, 145-157, 1999.

Margreth, S., Stoffel, L., and Wilhelm, C.: Winter opening of high alpine pass roads - analysis and case studies from the Swiss Alps, Cold Reg. Sc. 37, 467-482, 2003.

McClung, D. M.: Computer assistance in avalanche forecasting. Proceedings of the International Snow Science Workshop 1994, Snowbird, Utah, USA, 310-313, 1995a.

McClung, D. M.: Use of Expert Knowledge in Avalanche Forecasting, Def. Sc. J., 45, 117-123, 1995b.

McClung, D. M. and Schaerer, P. A.: The avalanche handbook, Seattle, 1993.

Mittra, S. S.: Decision Support Systems, Tools and Techniques, New York, 1986.

Rodriguez-Bachiller, A. and Glasson, J.: Expert systems and geographical information systems for impact assessment, London, 2004.
Sailer, R.: Risk Assessment and Crisis Management for a winter tourist resort (St. Anton a/A, Tyrol, Austria) - a case study. Proceedings of the First Annual IIASA-DPRI Meeting on Integrated Disaster Risk Management: Reducing Socio-Economic Vulnerability, IIASA, Laxenburg, Austria, 2001.

Schweizer, J. and Föhn, P.M.B.: Avalanche forecasting - an expert system approach, J. Glaciol., 42, 318-332, 1996.

Schweizer, M., Föhn, P. M. B., Schweizer, J., and Ultsch, A.: A Hybrid Expert System for Avalanche Forecasting, in: Information and Communication Technologies in Tourism, Edited by: Schertler, W., Schmid, B., Tjoa, A. M., and Werthner, H., New York, 148-153, 1994.

Sprague, R. H. J. and Watson, H. J.: Decision Support Systems, Putting Theory into Practice, London, 1986.

UN/ISDR: Living with Risk - A global review of disaster reduction initiatives, 2004 Version, 1, Geneva, 2004.

Wilhelm, C.: Wirtschaftlichkeit im Lawinenschutz, edited by SLF Eidgenössisches Institut für Schnee- und Lawinenforschung, Mitt. 54, Davos, 1997.

Zadeh, L. A.: Fuzzy sets. Inform. Contr., 8, 338-353, 1965.

Zadeh, L. A.: The concept of a linguistic variable and its application to approximate reasoning-I., Inform. Sc., 8, 199-249, 1975.

Zadeh, L. A., Fuzzy sets as a basis for a theory of possibility, Fuzzy Sets Syst., 1, 3-28, 1978.

Zimmermann, H. J.: Fuzzy Technologien. Prinzipien, Werkzeuge, Potentiale, Düsseldorf, 1993.

Zimmermann, H. J.: An application-oriented view of modelling uncertainty, Eur. J. Op. Res., 122, 190-198, 2000.

Zimmermann, M., Mani, P., and Gamma, P.: Murganggefahr und Klimaänderung - ein GIS-basierter Ansatz, Zürich, 1997.

Zischg, A.: Analyse des Systemverhaltens von Nassschneelawinen als Basis für die Generierung von dynamischen Gefahrenhinweissystemen am Beispiel der Ortlergruppe (Südtirol), Proc. Intern. Symp. Interpraevent 2004 - Riva del Garda, VI/229VI/240, 2004.

Zischg, A., Fuchs, S., Keiler, M., and J. Stötter: Temporal variability of damage potential on roads as a conceptual contribution towards a short-term avalanche risk simulation, Nat. Hazards Earth Syst. Sci., 5, 235-242, 2005,

SRef-ID: 1684-9981/nhess/2005-5-235.

Zischg, A., Fuchs, S., and Stötter, J.: Uncertainties and fuzziness in analysing risk related to natural hazards - A case study in the Ortles Alps, South Tyrol, Italy, in: Risk Analysis IV, edited by: Brebbia, C., Management Information Systems 9, Southampton, 523-532, 2004. 